\title{
"ASCALE FOR PSYCHOLOGICAL HESITATION OF POLE VAULT FOR FEMALE STUDENTS OF FACULTY OF PHYSICAL EDUCATION, UNIVERSITY OF AL-SADAT CITY"
}

\author{
Dr. Noha Mahmoud Mohamed El-Sawaf.
}

\section{- INTRODUCTION \& RESEARCH PROBLEM}

Psychological hesitation is an important psychological feature or status, playing an important role in controlling sporting achievement, and it is a basic element in learning dynamic skills, as a good psychological preparation helps to get over psychological strains, disputes and crisis by which an individual passes in general circumstances of life, especially in sports practices such as conditions of international competitions and learning difficult skills requiring risk. Psychological hesitation does not accompany an athlete all time; instead, it appears in variously difficult situations requiring decisiveness in taking a decision of required performance or leaving it.

There is an obvious relation between mental hesitation and muscular one. Every mental hesitation or strain affects muscles and every Muscular hesitation or cramp affects mental concentration. Therefore, one cannot enjoy a complete-psychological health, if there is mental hesitation during muscular activity (4: $16-20)$.

\section{- REASONS FOR PSYCOLOGICAL HESITATION IN SPORTS FIELD.}

1. Non-existence of balance between an athlete realization of environmental requirements and his realization to his abilities.

2. The way in which an athlete realize events (i.e. there are a positive realization for events in addition to a negative one).

3. An athlete response to environment in the shape of excitation that is considered a kind of activation.

The $3^{\text {rd }}$ element of hesitation is an athlete response to environment in the shape of excitation. This element is strongly related to behavior i.e. physiological, psychological and behavior changes happening to a person while being hesitated. Accordingly, hesitation involves 3 basic elements (environment - realizations - responses).

Competition of pile-vault is a complex one with big difficulties in performing, and it requires a high concentration from female students, to be able to perform this competition correctly. Researcher has noticed, through teaching this competition over many years that many female students intensively fear to perform this competition, although of their realization and understanding of nature of competition. They have an obvious state of hesitation while performing. Researcher sees that this hesitation results from being afraid of mockery of others and their blaming, in addition to being afraid of failure or injuries, and their negative thinking towards themselves. Therefore, researcher has made further research in scientific references and previous studies containing this problem. She found that this problem goes back to psychological hesitation of players. She also noticed, within limitations of her knowledge, non-existence of Egyptian studies containing this problem. This led researcher to do this study, aiming to build a scale for psychological hesitation of pile-vault competition for female students of faculty of physical education of Al-Sadat University, to understand reasons for affecting the education of this competition, in order for educational process of this competition to proceed properly.

Pole vaulting is one of the field events which contains complex moves, that requires high needs of physical, skill, and psychological qualifications (1:370)

Pole vault is the greatest event of athletics, it requires great effort and concentration as well as continuous hard training and good coach, who applies the scientific basis in training because of the complexity and difficulty of vaulting (11: 80)

\section{- OBJECTIVE OF RESEARCH.}

Building a scale for psychological hesitation of pole-vault competition for female students of faculty of physical education of Al-Sadat University being studied. 


\section{- QUESTION OF RESEARCH}

Is it possible to build a scale for psychological hesitation of pole-vault competition for female students in the $4^{\text {th }}$ stage in the faculty of physical education of Al-Sadat University?

\section{- RESEARCH PROCEDURES.}

- RESEARCH METHOD.

Researcher has used descriptive method for a single experimental group because of it suitability to the nature of the research.

- RESEARCH SAMPLE

Research sample has contained 80 female students in the $4^{\text {th }}$ stage in the faculty of physical education of Al-Sadat University, in the educational year 2014 / 2015.

TABLE NO (1)Description community and the research sample $\quad \mathrm{N}=80$

\begin{tabular}{c|c|c|c|c}
\hline Variables & Unit measure & mean & Std. Deviation & Skewness \\
\hline tall & c.m & 161.16 & 3.949 & .461 \\
\hline age & Year & 20.94 & .669 & .069 \\
\hline Wight & k.g & 59.45 & 7.790 & .252 \\
\hline
\end{tabular}

Table( 1 ) shows that the torsion coefficient of the sample in length, age and weight has been narrowed between $( \pm 3)$ which indicates the homogeneity of the sample in those variables individuals.

- SCALE USED IN RESEARCH.

To build and finish the scale, researcher depended on the following means:

- References of scientific resources.

- Seeing previous similar studies.

- Exploring opinions of experts.

- THE SCALE IN ITS PRIMARY PHASE (attachment No. 1).

The scale has involved (9) axes in its primary phase, with a total of (48) sentences which have been submitted to experts.

- THE SCALE IN ITS FINAL PHASE (attachment No. 2).

After the scale had been submitted to experts and statistical processing had been made, it has been agreed to definite axes of psychological hesitation phenomena. In addition, sentence No.(7-12-1420-22-27-30-37) has been removed, and sentence No.(2-23-16)has been amended. Therefore, the scale in its final phase has involved (40) sentences. All these sentences measure psychological hesitation accompanied to performing the competition being studied.

\section{- CALCULATING VALIDITY OF SCALE USING INTERNAL CONSISTENCY.}

Validity of scale has been calculated using validity of internal consistency between sentences of each axis and the total degree of an axis, and between the degree of each axis and the total degree of scale. This has been over research sample involving 80 female students of the $1^{\text {st }}$ stage. Both of next tables (2) and (3) show coefficients of correlation between degree of each sentence and the total degree of axis represented by the sentence, in addition to coefficients of correlation between degree of each axis and the total degree of scale.

Table (3) shows that there has been a statistically significant correlation between degree of each sentence and the total degree of axis. This indicates the validity of sentence representation to axis. 
TABLE NO. (2) correlation Between the degree of each phrase and total correlation coefficient Kidney axis represented by ferry $n=80$

\begin{tabular}{|c|c|c|c|c|c|c|c|}
\hline \multicolumn{2}{|c|}{$\begin{array}{l}\text { Axis thinking under } \\
\text { the burdens }\end{array}$} & \multicolumn{2}{|c|}{$\begin{array}{c}\text { Goal and past experiences } \\
\text { axis }\end{array}$} & \multicolumn{2}{|c|}{$\begin{array}{c}\text { Axis change the place of } \\
\text { performance and the impact of } \\
\text { public }\end{array}$} & \multicolumn{2}{|c|}{$\begin{array}{c}\text { Axis of providing security } \\
\text { elements }\end{array}$} \\
\hline No & $\begin{array}{l}\text { value } \\
\text { "R " }\end{array}$ & No & $\begin{array}{l}\text { value } \\
\text { "R " }\end{array}$ & No & $\begin{array}{l}\text { value } \\
\text { "R " }\end{array}$ & No & $\begin{array}{l}\text { value } \\
\text { "R " }\end{array}$ \\
\hline 1 & $* .686$ & 1 & $* 672$ & 1 & $* 680$ & 1 & $* .679$ \\
\hline 2 & $* .675$ & 2 & *.676 & 2 & $* .778$ & 2 & $* .753$ \\
\hline 3 & $* .661$ & 3 & $* .758$ & 3 & *.689 & 3 & $* .677$ \\
\hline 4 & $* .654$ & 4 & *.686 & 4 & *.670 & 4 & $* .651$ \\
\hline 5 & $* .671$ & 5 & $* .679$ & & & & \\
\hline 6 & $* .656$ & 6 & $* .785$ & & & & \\
\hline 7 & $* .673$ & & & & & & \\
\hline \multicolumn{2}{|c|}{$\begin{array}{l}\text { The focus of the } \\
\text { teacher's role and } \\
\text { impact of the } \\
\text { reward and } \\
\text { encouragement }\end{array}$} & \multicolumn{2}{|c|}{$\begin{array}{l}\text { Axis level and the } \\
\text { importance of competition }\end{array}$} & \multicolumn{2}{|c|}{ Axis feeling bored } & \multicolumn{2}{|c|}{$\begin{array}{l}\text { Axis knowledge of the } \\
\text { person and its potential }\end{array}$} \\
\hline No & $\begin{array}{l}\text { value } \\
\text { "R " }\end{array}$ & No. ferry & $\begin{array}{l}\text { value } \\
\text { "R " }\end{array}$ & No & $\begin{array}{l}\text { value } \\
\text { "R " }\end{array}$ & No & $\begin{array}{l}\text { value } \\
\text { "R " }\end{array}$ \\
\hline 1 & $* .701$ & 1 & $* .670$ & 1 & $* .760$ & 1 & $* .784$ \\
\hline 2 & $* .654$ & 2 & $* .690$ & 2 & $* .666$ & 2 & $* .661$ \\
\hline 3 & $* .665$ & 3 & $* .668$ & 3 & $* .793$ & 3 & $* .690$ \\
\hline 4 & $* .755$ & 4 & $* .662$ & 4 & $* .688$ & & \\
\hline \multicolumn{2}{|c|}{$\begin{array}{l}\text { Axis physical style } \\
\text { and training case }\end{array}$} & & & & & & \\
\hline No & $\begin{array}{l}\text { value } \\
\text { "R " }\end{array}$ & & & & & & \\
\hline 1 & $* .782$ & & & & & & \\
\hline 2 & $* .765$ & & & & & & \\
\hline 3 & $* .755$ & & & & & & \\
\hline 4 & $* .685$ & & & & & & \\
\hline
\end{tabular}

Value of(r) is(.217) 
Table (3) statistically significant correlation between degree of each axis and the total degree of scale $\mathrm{N}=(80)$

\begin{tabular}{r|c}
\multicolumn{1}{c|}{ Scale axes } & R value \\
\hline Axis thinking under the burdens & $* .661$ \\
\hline Goal and past experiences axis & $* .722$ \\
\hline Axis change the place of performance and the & $* .659$ \\
\hline Axis of providing security elements & $* .698$ \\
\hline The focus of the teacher's role and impact of the & $* .769$ \\
\hline Axis level and the importance of competition & $* .674$ \\
\hline Axis feeling bored & $* .683$ \\
\hline Axis knowledge of the person and its potential & $* .665$ \\
\hline
\end{tabular}

Value of(r) is (.217)

Table (3) show that there have been a statistically significant correlation between degree of each axis and the total degree of scale $(\mathrm{N}=80)$. This indicates the validity of axes representation to scale.

\section{- CALCULATING COEFFICIENT OF SCALE STABILITY USING "ALPHA"} COEFFICIENT.

Table (4) statistically significant using alpha $\mathrm{N}=(80)$

\begin{tabular}{|c|c|c|}
\hline Scale axes & Number of ferry & ALPHA value \\
\hline Axis thinking under the burdens & 7 & $* .688$ \\
\hline Goal and past experiences axis & 6 & $* .602$ \\
\hline Axis change the place of performance and the impact of public & 4 & ${ }^{*} .612$ \\
\hline Axis of providing security elements & 4 & $* .766$ \\
\hline $\begin{array}{r}\text { The focus of the teacher's role and impact of the reward and } \\
\text { encouragement }\end{array}$ & 4 & $\star .767$ \\
\hline Axis level and the importance of competition & 4 & $* .643$ \\
\hline Axis feeling bored & 4 & $* .752$ \\
\hline Axis knowledge of the person and its potential & 3 & $* .778$ \\
\hline Axis physical style and training case & 4 & $* .654$ \\
\hline
\end{tabular}

Value of(R) is(.217)

Coefficient of psychological-hesitation stability has been calculated using "Alpha" coefficient, according to amendment of Cronbach. Table (4) shows values of stability coefficient. 
Table (4 shows that all axes of psychological-hesitation scale have high values of "Alpha" coefficient, indicating the stability of scale.

- PRESENTATION \& DISCUSSION OF RESULTS.

Table (5) Duplicates and ratios improved and the value of "X2" and the relative importance of psychological phrases frequency

\begin{tabular}{|c|c|c|c|c|c|c|c|c|c|}
\hline \multirow{2}{*}{$\mathbf{N}$} & \multicolumn{2}{|c|}{ Apply completely } & \multicolumn{2}{|c|}{ Apply sometimes } & \multicolumn{2}{|c|}{ Does not apply never } & \multirow{2}{*}{$\begin{array}{c}\text { chi } \\
\text { square }\end{array}$} & \multirow{2}{*}{$\begin{array}{c}\text { Importance } \\
\text { Relative }\end{array}$} & \multirow[t]{2}{*}{ Ranking } \\
\hline & Repetition & parentage & Repetition & parentage & Repetition & parentage & & & \\
\hline 1 & 39 & $\% 48.75$ & 21 & $\% 26.25$ & 20 & $\% 25$ & $* 8.757$ & 47.58 & 13 \\
\hline 2 & 27 & $\% 33.75$ & 25 & $\% 31.25$ & 28 & $\% 35$ & .175 & 66.25 & 23 \\
\hline 3 & 27 & $\% 33.75$ & 42 & $\% 52.5$ & 11 & $\% 13.75$ & $* 18.025$ & 73.33 & 14 \\
\hline 4 & 4 & $\% 5$ & 26 & $\% 78.25$ & 50 & $\% 16.75$ & $* 39.700$ & 47.5 & 38 \\
\hline 5 & 46 & $\% 17.5$ & 21 & $\% 26.45$ & 13 & $\% 16.75$ & $* 22.225$ & 80.42 & 8 \\
\hline 6 & 5 & $\% 6.25$ & 23 & $\% 28.75$ & 52 & $\% 65$ & $* 42.175$ & 47.08 & 37 \\
\hline 7 & 39 & $\% 48.75$ & 32 & $\% 40$ & 9 & $\% 11.25$ & $* 18.475$ & 79.17 & 10 \\
\hline 8 & 10 & $\% 12.5$ & 45 & $\% 56.25$ & 25 & $\% 31.25$ & $* 23.125$ & 60.42 & 31 \\
\hline 9 & 34 & $\% 42.5$ & 6 & $\% 7.5$ & 40 & $\% 50$ & $* 24.700$ & 64.17 & 26 \\
\hline 10 & 13 & $\% 16.25$ & 48 & $\% 60$ & 19 & $\% 23$ & $* 26.275$ & 47.5 & 38 \\
\hline 11 & 49 & $\% 16.25$ & 28 & $\% 23.75$ & 13 & $\% 16.25$ & $* 12.775$ & 90 & 1 \\
\hline 12 & 21 & $\% 26.25$ & 44 & $\% 55$ & 15 & $\% 18.75$ & $* 17.757$ & 69.17 & 19 \\
\hline 13 & 19 & $\% 23.75$ & 31 & $\% 38.75$ & 30 & $\% 37.5$ & 3.325 & 62.08 & 29 \\
\hline 14 & 11 & $\% 13.75$ & 35 & $\% 43.75$ & 34 & $\% 42.5$ & $* 3.825$ & 57.08 & 33 \\
\hline 15 & 49 & $\% 61.25$ & 23 & $\% 28.75$ & 8 & $\% 10$ & $* 2.275$ & 83.75 & 5 \\
\hline 16 & 47 & $\% 58.75$ & 25 & $\% 31.75$ & 4 & $\% 5$ & $* 34.975$ & 81.25 & 7 \\
\hline 17 & 33 & $\% 41.25$ & 47 & $\% 58.75$ & - & - & 2.450 & 81.25 & 8 \\
\hline 18 & 32 & $\% 40$ & 10 & $\% 12.5$ & 38 & $\% 47.5$ & $* 16.300$ & 64.17 & 26 \\
\hline 19 & 14 & $\% 17.5$ & 32 & $\% 40$ & 34 & $\% 42.5$ & $* 9.100$ & 58.33 & 32 \\
\hline 20 & 10 & $\% 12.5$ & 49 & $\% 61.25$ & 21 & $\% 26.25$ & $* 30.325$ & 62.08 & 29 \\
\hline 21 & 19 & $\% 23.75$ & 34 & $\% 42.5$ & 27 & $\% 33.75$ & 4.225 & 63.33 & 28 \\
\hline 22 & 13 & $\% 16.25$ & 26 & $\% 32.5$ & 41 & $\% 51.25$ & $* 14,725$ & 55 & 34 \\
\hline 23 & 48 & $\% 60$ & 27 & $\% 33.75$ & 5 & $\% 6.25$ & $* 34.675$ & 48.58 & 4 \\
\hline 24 & 25 & $\% 31.25$ & 37 & $\% 41.25$ & 18 & $\% 22.5$ & $* 6.925$ & 96.58 & 18 \\
\hline 25 & 55 & $\% 68.75$ & 25 & $\% 31.25$ & - & - & $* 11.250$ & 89.58 & 2 \\
\hline 26 & 22 & $\% 27.5$ & 50 & $\% 62.5$ & 8 & $\% 10$ & $* 34.300$ & 72.5 & 16 \\
\hline 27 & 12 & $\% 15$ & 20 & $\% 25$ & 48 & $\% 60$ & $* 26.800$ & 51.67 & 35 \\
\hline 28 & 12 & $\% 15$ & 54 & $\% 67.5$ & 14 & $\% 17.5$ & $* 42.100$ & 65.83 & 25 \\
\hline 29 & 38 & $\% 47.5$ & 17 & $\% 21.25$ & 25 & $\% 31.25$ & $* 8.425$ & 87.77 & 3 \\
\hline 30 & 49 & $\% 61.25$ & 23 & $\% 28.75$ & 8 & $\% 10$ & $* 32.275$ & 83.75 & 5 \\
\hline 31 & 25 & $\% 31.25$ & 38 & $\% 47.5$ & 17 & $\% 21.25$ & $* 8.425$ & 70 & 17 \\
\hline 32 & 24 & $\% 30$ & 56 & $\% 70$ & - & - & $* 12.800$ & 76.67 & 11 \\
\hline 33 & 33 & $\% 41.25$ & 27 & $\% 33.75$ & 20 & $\% 25.25$ & 3.175 & 72.08 & 15 \\
\hline 34 & 20 & $\% 25$ & 44 & $\% 55$ & 16 & $\% 20$ & $* 17.200$ & 68.33 & 20 \\
\hline 35 & 38 & $\% 47.5$ & 31 & $\% 38.75$ & 11 & $\% 13.75$ & $* 14.725$ & 77.92 & 10 \\
\hline 36 & 28 & $\% 35$ & 23 & $\% 28.75$ & 29 & $\% 36.25$ & .775 & 66.25 & 23 \\
\hline 37 & 24 & $\% 30$ & 56 & $\% 70$ & - & - & $* 12.800$ & 76.67 & 11 \\
\hline 38 & 24 & $\% 30$ & 32 & $\% 40$ & 24 & $\% 30$ & 1.600 & 67.66 & 22 \\
\hline 39 & 23 & $\% 28.75$ & 39 & $\% 48.75$ & 17 & $\% 28.25$ & $* 37$ & 68.33 & 20 \\
\hline 40 & 17 & $\% 21.25$ & 25 & $\% 31.25$ & 18 & $\% 22.5$ & $* 18.925$ & 49.58 & 36 \\
\hline
\end{tabular}

Sig value of chi square (5.99)

Table (5) shows that calculated value of (chi square), which is (8.757), is larger than its table value, which is (5.99), indicating difference between answers of $1^{\text {st }}$ sentence in direction of answer (completely applies) having a percentage of (48.75\%) of total answers.

Results of table (5) also show that calculated value of (chi square), which is (0.175), is less than its table value, which is (5.99), indicating insignificant difference between answers of $2^{\text {nd }}$ sentence in direction of answer (completely not applies) having a percentage of $(35.00 \%)$ of total answers. 
Results of table (5) also show that calculated value of (chi square), which is (18.025), is larger than its table value, which is (5.99), indicating difference between answers of $3^{\text {rd }}$ sentence in direction of answer(occasionally applies) having a percentage of (52.5\%) of total answers.

Results of table (5) also show that calculated value of (chi square), which is (39.700), is larger than its table value, which is (5.99), indicating difference between answers of $4^{\text {th }}$ sentence in direction of answer (completely not applies) having a percentage of $(62.5 \%)$ of total answers.

Results of table (5) also show that calculated value of (chi square), which is (22.225), is larger than its table value, which is (5.99), indicating difference between answers of $5^{\text {th }}$ sentence in direction of answer (completely applies) having a percentage of (57.5\%) of total answers.

Results of table (5) also show that calculated value of (chi square), which is (42.175), is larger than its table value, which is (5.99), indicating difference between answers of $6^{\text {th }}$ sentence in direction of answer (completely not applies) having a percentage of $(65 \%)$ of total answers.

Results of table (7) also show that calculated value of (chi square), which is (42.175), is larger than its table value, which is (5.99), indicating difference between answers of $7^{\text {th }}$ sentence in direction of answer (completely applies) having a percentage of $(48.75 \%)$ of total answers.

Results of table (5) also show that calculated value of (chi square), which is (23.125), is larger than its table value, which is (5.99), indicating difference between answers of $8^{\text {th }}$ sentence in direction of answer (occasionally applies) having a percentage of $(65.25 \%)$ of total answers.

Results of table (5) also show that calculated value of (chi square), which is (24.700), is larger than its table value, which is (5.99), indicating difference between answers of $9^{\text {th }}$ sentence in direction of answer (completely applies) having a percentage of (50\%) of total answers.

Results of table (5) also show that calculated value of (chi square), which is (3.335), is larger than its table value, which is (5.99), indicating a non-functional difference between answers of $10^{\text {th }}$ sentence in direction of answer (occasionally applies) having a percentage of $(83.75 \%)$ of total answers.

Results of table (5) also show that calculated value of (chi square), which is (12.775), is larger than its table value, which is (5.99), indicating difference between answers of $11^{\text {th }}$ sentence in direction of answer (completely applies) having a percentage of (17.575\%) of total answers.

Results of table (5) also show that calculated value of (chi square), which is (17.575), is larger than its table value, which is (5.99), indicating difference between answers of $12^{\text {th }}$ sentence in direction of answer (occasionally applies) having a percentage of (55\%) of total answers.

Results of table (5) also show that calculated value of (chi square), which is (26.275), is larger than its table value, which is (5.99), indicating difference between answers of $13^{\text {th }}$ sentence in direction of answer (occasionally applies) having a percentage of $(60 \%)$ of total answers.

Results of table (5) also show that calculated value of (chi square), which is (13.825), is larger than its table value, which is (5.99), indicating difference between answers of $14^{\text {th }}$ sentence in direction of answer (occasionally applies) having a percentage of $(43.75 \%)$ of total answers.

Results of table (5) also show that calculated value of (chi square), which is (32.75), is larger than its table value, which is (5.99), indicating difference between answers of $15^{\text {th }}$ sentence in direction of answer (completely applies) having a percentage of (61.25\%) of total answers.

Results of table (5) also show that calculated value of (chi square), which is (34.975), is larger than its table value, which is (5.99), indicating difference between answers of $16^{\text {th }}$ sentence in direction of answer (completely applies) having a percentage of (58.75\%) of total answers (completely applies).

Results of table (7) also show that calculated value of (chi square), which is (2.45), is less than its table value, which is (5.99), indicating non-functional difference between answers of $17^{\text {th }}$ sentence in direction of answer (occasionally applies) having a percentage of $(58.75 \%)$ of total answers.

Results of table (5) also show that calculated value of (chi square), which is (16.30), is larger than its table value, which is (5.99), indicating difference between answers of $18^{\text {th }}$ sentence in direction of answer (completely not applies) having a percentage of $(47.5 \%)$ of total answers.

Results of table (5) also show that calculated value of (K2), which is (9.10), is larger than its table value, which is (5.99), indicating difference between answers of $19^{\text {th }}$ sentence in direction of answer (completely not applies) having a percentage of (42.5\%) of total answers. 
Results of table (5) also show that calculated value of (chi square), which is (30.325), is larger than its table value, which is (5.99), indicating difference between answers of $20^{\text {th }}$ sentence in direction of answer (occasionally applies) having a percentage of $(61.25 \%)$ of total answers.

Results of table (5) also show that calculated value of (chi square), which is (4.225), is less than its table value, which is (5.99), indicating statistically non-functional differences between answers of $21^{\text {th }}$ sentence in direction of answer (occasionally applies) having a percentage of $(42.5 \%)$ of total answers.

Results of table (5) also show that calculated value of (chi square), which is (14.725), is larger than its table value, which is (5.99), indicating difference between answers of $22^{\text {th }}$ sentence in direction of answer (completely applies) having a percentage of (51.25\%) of total answers.

Results of table (5) also show that calculated value of (chi square), which is (34.675), is larger than its table value, which is (5.99), indicating difference between answers of $23^{\text {th }}$ sentence in direction of answer (completely applies) having a percentage of (60\%) of total answers.

Results of table (5) also show that calculated value of (chi square), which is (6.925), is larger than its table value, which is (5.99), indicating difference between answers of $24^{\text {th }}$ sentence in direction of answer (occasionally applies) having a percentage of (46.25\%) of total answers.

Results of table (5) also show that calculated value of (chi square), which is (11.250), is larger than its table value, which is (5.99), indicating difference between answers of $25^{\text {th }}$ sentence in direction of answer (completely applies) having a percentage of (68.75\%) of total answers.

Results of table (5) also show that calculated value of (chi square), which is (34.300), is larger than its table value, which is (5.99), indicating difference between answers of $26^{\text {th }}$ sentence in direction of answer (occasionally applies) having a percentage of $(62.5 \%)$ of total answers.

Results of table (5) also show that calculated value of (chi square), which is (26.800), is larger than its table value, which is (5.99), indicating difference between answers of $27^{\text {th }}$ sentence in direction of answer (completely not applies) having a percentage of $(60 \%)$ of total answers.

Results of table (5) also show that calculated value of chi square), which is (42.100), is larger than its table value, which is (5.99), indicating difference between answers of $28^{\text {th }}$ sentence in direction of answer (occasionally applies) having a percentage of $(67.5 \%)$ of total answers.

Results of table (5) also show that calculated value of (chi square), which is (8.425), is larger than its table value, which is (5.99), indicating difference between answers of $29^{\text {th }}$ sentence in direction of answer (completely applies) having a percentage of (47.5\%) of total answers.

Results of table (5) also show that calculated value of (chi square), which is (32.275), is larger than its table value, which is (5.99), indicating difference between answers of $30^{\text {th }}$ sentence in direction of answer (completely applies) having a percentage of (61.25\%) of total answers.

Results of table (5) also show that calculated value of chi square), which is (8.425), is larger than its table value, which is (5.99), indicating difference between answers of $31^{\text {th }}$ sentence in direction of answer (occasionally applies) having a percentage of $(47.5 \%)$ of total answers.

Results of table (5) also show that calculated value of (chi square), which is (12.800), is larger than its table value, which is (5.99), indicating difference between answers of $32^{\text {th }}$ sentence in direction of answer (occasionally applies) having a percentage of (70\%) of total answers.

Results of table (5) also show that calculated value of (chi square), which is (3.715), is less than its table value, which is (5.99), indicating insignificant difference between answers of $33^{\text {th }}$ sentence in direction of answer (completely applies) having a percentage of $(41.25 \%)$ of total answers.

Results of table (5) also show that calculated value of (chi square), which is (17.00), is larger than its table value, which is (5.99), indicating difference between answers of $34^{\text {th }}$ sentence in direction of answer (occasionally applies) having a percentage of (55\%) of total answers.

Results of table (5) also show that calculated value of (chi square), which is (0.775), is less than its table value, which is (5.99), indicating insignificant difference between answers of $36^{\text {th }}$ sentence in direction of answer (completely not applies) having a percentage of (36.75\%) of total answers.

Results of table (5) also show that calculated value of (chi square), which is (12.800), is larger than its table value, which is (5.99), indicating difference between answers of $37^{\text {th }}$ sentence in direction of answer (completely applies) having a percentage of (70\%) of total answers. 
Results of table (5) also show that calculated value of (chi square), which is (1.600), is less than its table value, which is (5.99), indicating insignificant difference between answers of $38^{\text {th }}$ sentence in direction of answer (occasionally applies) having a percentage of (40\%) of total answers.

Results of table (5) also show that calculated value of (chi square), which is (37.00), is larger than its table value, which is (5.99), indicating difference between answers of $39^{\text {th }}$ sentence in direction of answer (occasionally applies) having a percentage of $(48.75 \%)$ of total answers.

Results of table (5) also show that calculated value of (chi square), which is (18.925), is larger than its table value, which is (5.99), indicating difference between answers of $40^{\text {th }}$ sentence in direction of answer (occasionally applies) having a percentage of (31.25\%) of total answers.

\section{- DISCUSSION OF RESULTS}

Discussing results of sentence No. (1): Sometimes, I feel not want to practice sports activity.

Results show the existence of statistically significant differences in direction of the answer (completely applies) having a percentage of $(48.75 \%)$ of total answers. Its relative importance has been (74.58), and its rating, with respect to sentences of scale, has been (13).

Researcher attributes this result to the desire in practicing sports activity that plays an important role in performance-ability of an individual. It is normal that psychological status and mood affect the desire of any person practicing sports activity.

Discussing results of sentence No. (2): I am bored with competition.

Results show the existence of statistically insignificant differences in direction of the answer (completely not applies) having a percentage of (35\%) of total answers. Its relative importance has been (66.25), and its rating, with respect to sentences of scale, has been (23).

Researcher attributes boredom to that feeling bored with practice has two reasons, either repeated tries accompanied by failure, or repeated tries accompanied by success and feeling that repetition is useless. However, through researcher's experience, she suggests the first possibility to be the correct one, because of difficulty of competition and its numerous technical requirements. Many people continue trying aiming at success, and so, they do not get bored easily.

Discussing results of sentence No. (3): Repetition of practice makes me not want to continue practicing.

Results show the existence of statistically significant differences in direction of the answer (occasionally applies) having a percentage of (52.5\%) of total answers. Its relative importance has been (73.32), and its rating, with respect to sentences of scale, has been (14).

Researcher attributes the result to that many female students face difficulties in practice and feel fright. As a result, they prefer not to repeat practice.

Discussing results of sentence No. (4): Practicing for a long time makes me not want to implement steps of competition.

Results show the existence of statistically significant differences in direction of the answer (completely not applies) having a percentage of (62.5\%) of total answers. Its relative importance has been (47.5), and its rating, with respect to sentences of scale, has been (38).

Researcher attributes this result to that difficulty of this competition, in comparison to other ones, makes some female students want to enlarge duration of study of this competition, trying to reach a proper performance requiring too much training.

Discussing results of sentence No. (5): I am afraid of device and that I am not able to perform on it.

Results show the existence of statistically significant differences in direction of the answer (completely applies) having a percentage of (57.5\%) of total answers. Its relative importance has been (80.42), and its rating, with respect to sentences of scale, has been (8).

Researcher attributes this result to most female students being afraid of jumping using the pile especially that they had not practiced any similar sport before.

Discussing results of sentence No. (6): When I understand the purpose for a competition, I perform it easily. 
Results show the existence of statistically significant differences in direction of the answer (completely not applies) having a percentage of (65\%) of total answers. Its relative importance has been (47.08), and its rating, with respect to sentences of scale, has been (37).

Researcher attributes these differences and percentage to that female students' recognition of purpose for a competition does not help them to overcome their fears, and makes them feel the importance of technical requirements to which they need.

Discussing results of sentence No. (7): I fear not to put the pole in its right place within the $\underline{\text { box. }}$

Results show the existence of statistically significant differences in direction of the answer (completely applies) having a percentage of (48.75\%) of total answers. Its relative importance has been (79.19), and its rating, with respect to sentences of scale, has been (10).

Researcher, through her experience in teaching this competition for many years, attributes this result to that female students fear not to put the pole in its right place. This represents their biggest obsession, as they worry about consequent injuries.

Discussing results of sentence No. (8): Difficulty of performance skills makes me fear practice. Results show the existence of statistically significant differences in direction of the answer (completely not applies) having a percentage of $(56.25 \%)$ of total answers. Its relative importance has been (60.42), and its rating, with respect to sentences of scale, has been (31).

Researcher sees that this is the actual thinking of many female students because of the difficulty of technical stages of pole-vault in comparison to other competitions being studied. This affects their study of the competition negatively.

Discussing results of sentence No. (9): My experience and practice of athletics make me not afraid of pole-vault competition.

Results show the existence of statistically significant differences in direction of the answer (completely not applies) having a percentage of (50\%) of total answers. Its relative importance has been (64.17), and its rating, with respect to sentences of scale, has been (26).

Researcher attributes this result to that technical performance of pole-vault is not similar to technical performance of other competitions As a result, their experience of athletics does not prevent their fear of this competition.

Discussing results of sentence No. (10): My understanding to technical stages makes me perform the competition.

Results show the existence of statistically insignificant differences between answers, as most female students understand nature of practice and look forward to execution with understanding technical stages. However, many of them put difficulty of performance as an obstacle for understanding and the try to perform. Many others try, but they are affected by other factors such as fear and lack of self-confidence preventing making use of their understanding to the nature of performance, and they become unable to perform as a result.

Discussing results of sentence No. (11): I worry about mockery of others while performing.

Results show the existence of statistically significant differences in direction of the answer (completely applies) having a percentage of (61.25\%) of total answers. Its relative importance has been (90), and its rating, with respect to sentences of scale, has been (1).

This goes back to the nature of girls and their shyness because of mockery of others. So, this prevents trying to perform.

Discussing results of sentence No. (12): I do not have self-confidence to perform this competition.

Results show the existence of statistically significant differences in direction of the answer (occasionally applies) having a percentage of $(55 \%)$ of total answers. Its relative importance has been (69.16), and its rating, with respect to sentences of scale, has been (19).

Researcher attributes this result to that many female students do not have self-confidence, because of many factors such as their physical and skill level, so this point represents an obstacle for the required performance. However, many others do not think about anything other than success, so 
they do their best to overcome fear and lack of self-confidence, seeking the right performance. Many of them have a complete self-confidence helping then to overcome any difficulties.

Discussing results of sentence No. (13): My pulse increases just before performing.

Results show the existence of statistically significant differences in direction of the answer (occasionally applies) having a percentage of $(60 \%)$ of total answers. Its relative importance has been (62.08), and its rating, with respect to sentences of scale, has been (29).

Researcher attributes this result to those female students, who are able to perform, always worry about failure, and they try to reach a better result. Accordingly, their pulse increases as they worry about dereliction or not maintaining their level, in addition to their desire in success. Increasing pulse of many others, who fear performing and fail it, is attributed to their fear of performance itself, whether it is fear of failure, injury or inability to perform.

Discussing results of sentence No. (14): I cannot take the decision of jumping when it is required.

Results show the existence of statistically significant differences in direction of the answer (occasionally applies) having a percentage of (43.75\%) of total answers. Its relative importance has been (57.08), and its rating, with respect to sentences of scale, has been (33).

Researcher attributes this result to that many female students are affected by variable situations of performance. Many of them perform well during lectures and affected when lecturer asks them to perform. Performance may be related to degrees.

Discussing results of sentence No. (15): Repeating failure results in disappointment and inability to perform.

Results show the existence of statistically significant differences in direction of the answer (completely applies) having a percentage of $(61.25 \%)$ of total answers. Its relative importance has been (83.79), and its rating, with respect to sentences of scale, has been (5).

Researcher attributes this result to that failure usually represents an obstacle for try and success. Associating difficulty of performance with repeated failure, in their mind, frustrates them and makes them hopeless to succeed in performance.

Discussing results of sentence No. (16): I cannot perform competition when I am disappointed. Results show the existence of statistically significant differences in direction of the answer (completely applies) having a percentage of $(58.75 \%)$ of total answers. Its relative importance has been (81.25), and its rating, with respect to sentences of scale, has been (7).

Researcher attributes this result to that failure usually affects performance negatively. Female students, who can perform in addition to those who cannot perform, fail when they are disappointed.

Discussing results of sentence No. (17): Feeling confused and instable makes me afraid of performance.

Results show the existence of statistically insignificant differences in direction of the answer (occasionally applies) having a percentage of (58.75\%) of total answers. Its relative importance has been (80.42), and its rating, with respect to sentences of scale, has been (8).

Researcher attributes this result to that most female students worry about performing under unstable circumstances that obstacle their concentration in performance.

Discussing results of sentence No. (18): I feel afraid as I do not like pile-vault competition.

Results show the existence of statistically significant differences in direction of the answer (completely not applies) having a percentage of (47.50\%) of total answers. Its relative importance has been (64.17), and its rating, with respect to sentences of scale, has been (26).

Researcher attributes the result to that female students consider the competition as a means determining if they will succeed, so, they do not think to love it. They only perform this competition seeking academic success.

Discussing results of sentence No. (19): I do not care about my result of performance.

Results show the existence of statistically significant differences in direction of the answer (completely not applies) having a percentage of (42.50\%) of total answers. Its relative importance has been (58.33), and its rating, with respect to sentences of scale, has been (32). 
Researcher attributes the result to that their practice to this competition does not represent a personal desire but is required for success. Therefore, the result of performance is important for them.

Discussing results of sentence No. (20): I cannot control my temper in performance competitive situations.

Results show the existence of statistically significant differences in direction of the answer (occasionally applies) having a percentage of (61.25\%) of total answers. Its relative importance has been (62.08), and its rating, with respect to sentences of scale, has been (29).

Researcher attributes this result to that many female students are affected by the importance of competition. Many others worry about exams.

Discussing results of sentence No. (21): I worry about performing with higher-performance colleagues.

Results show the existence of statistically insignificant differences in direction of the answer (occasionally applies) by (42.5\%) of total answers. Its relative importance has been (63.33), and its rating, with respect to sentences of scale, has been (28).

Researcher attributes small differences between answers to that most female students think only of their personal success regardless of level of results of others. Many of them are positively affected when they notice results of their successful colleagues, and try to reach their level. Many others are negatively affected when comparing their level to levels of better ones.

Discussing results of sentence No. (22): My fitness is not good; it makes me afraid of performance.

Results show the existence of statistically insignificant differences in direction of the answer (completely not applies) having a percentage of (51.25\%) of total answers. Its relative importance has been (55), and its rating, with respect to sentences of scale, has been (34).

Researcher attributes the result to that female students are in the $4^{\text {th }}$ stage, and they have had a good physical preparation, in addition to that the technical part of each lecture is done after a good warm up and physical preparation.

Discussing results of sentence No. (23): I worry about performance, while I am tired.

Results show the existence of statistically significant differences in direction of the answer (completely applies) having a percentage of (60\%) of total answers. Its relative importance has been (84.58), and its rating, with respect to sentences of scale, has been (4).

Researcher sees that competition of pile-vault needs a high physical preparation because of the difficulty of its performance. It is normal for fatigue to affect performance and so female students worry about performance while being tired.

Discussing results of sentence No. (24): My body style makes me disappointed about performance.

Results show the existence of statistically-functional differences in direction of the answer (occasionally applies) having a percentage of (46.25\%) of total answers. Its relative importance has been (69.58), and its rating, with respect to sentences of scale, has been (18).

Researcher attributes the result to that female students have a negative impression about their bodies leading them to feel disappointed and unable to perform.

Discussing results of sentence No. (25): I worry about performance because of fatigue.

Results show the existence of statistically significant differences in direction of the answer (completely applies) having a percentage of (68.75\%) of total answers. Its relative importance has been (69.58), and its rating, with respect to sentences of scale, has been (2).

Researcher sees that this result is normal as fatigue generally represents an obstacle for sports activity and especially for difficult competitions.

Discussing results of sentence No. (26): I cannot perform competition because males exist in playground.

Results show the existence of statistically significant differences in direction of the answer (occasionally applies) having a percentage of (62.5\%) of total answers. Its relative importance has been (72.5), and its rating, with respect to sentences of scale, has been (16). 
Researcher attributes this result to that most female students make shy because of existence of males in playground and watching them while training. Many others only pay attention to performance, not to external factors.

Discussing results of sentence No. (27): My shyness results in my inability to perform pilevault competition.

Results show the existence of statistically significant differences in direction of the answer (occasionally applies) having a percentage of $(60 \%)$ of total answers. Its relative importance has been (51.67), and its rating, with respect to sentences of scale, has been (37).

Researcher attributes this result to that shyness is characteristic to girls, and it is normal to affect them while performing a difficult and new competition with respect to them, especially while the existence of others within the playground, such as lecturers and male colleagues, leading some of them to make shy in case of failure.

Discussing results of sentence No. (28): I cannot perform in the presence of too many spectators.

Results show the existence of statistically significant differences in direction of the answer (occasionally applies) having a percentage of (67.5\%) of total answers. Its relative importance has been (65.83), and its rating, with respect to sentences of scale, has been (25).

Researcher attributes this result to that many students got hesitated while being watched by a number of spectators, specially their colleagues of the $4^{\text {th }}$ stage. This affects their performance.

Discussing results of sentence No. (29): I worry and hesitate if place of training is changed.

Results show the existence of statistically significant differences in direction of the answer (completely applies) having a percentage of (47.5\%) of total answers. Its relative importance has been (87.77), and its rating, with respect to sentences of scale, has been (3).

Researcher attributes this result to that performance of female students is associated to place of training. Changing place of direction may affect them.

Discussing results of sentence No. (30): Existence of utilities motivates me to perform without fear.

Results show the existence of statistically significant differences in direction of the answer (completely applies) having a percentage of (61.25\%) of total answers. Its relative importance has been (83.75), and its rating, with respect to sentences of scale, has been (5).

Researcher attributes this result to that beginner female students need to utilities that motivate them to perform and give them trust.

Discussing results of sentence No. (31): Presence of assistants makes me feel comfortable while performing.

Results show the existence of statistically significant differences in direction of the answer (occasionally applies) having a percentage of (47.5\%) of total answers. Its relative importance has been (70), and its rating, with respect to sentences of scale, has been (17).

Researcher attributes this result to that many female students prefer the presence of a person helping them with performance. This gives them more trust and safety, although many others do not prefer this.

Discussing results of sentence No. (32): Being afraid of injury makes me worry about performance.

Results show the existence of statistically significant differences in direction of the answer (occasionally applies) having a percentage of (70\%) of total answers. Its relative importance has been (76.67), and its rating, with respect to sentences of scale, has been (11).

Researcher attributes this result to that difficulty of performance reflects possibility of injuries to female students. Many others do not pay any attention to this matter and insist on the right performance.

Discussing results of sentence No. (33): Mattresses are bad and make me feel worried about injury. 
Results show the existence of statistically insignificant differences in direction of the answer (completely applies) having a percentage of $(41.25 \%)$ of total answers. Its relative importance has been (72.08), and its rating, with respect to sentences of scale, has been (15).

Researcher attributes this result to that sound mattresses which are laid properly make female students feel safe, otherwise their performance are affected and they become worried.

Discussing results of sentence No. (34): My week relation to lecturer makes my worry about performance.

Results show the existence of statistically significant differences in direction of the answer (occasionally applies) having a percentage of (55\%) of total answers. Its relative importance has been (68.33), and its rating, with respect to sentences of scale, has been (20).

Researcher attributes this result to that female students' trust in their lecturer beside their love to her give them trust in performance and motivation to succeed.

Discussing results of sentence No. (35): Encouragement helps me with performance.

Results show the existence of statistically significant differences in direction of the answer (completely applies) having a percentage of (47.5\%) of total answers. Its relative importance has been (77.92), and its rating, with respect to sentences of scale, has been (10).

Researcher attributes this result to that female students' trust always get excited when they are encouraged.

Discussing results of sentence No. (36): I feel worried when lecturer is changed.

Results show the existence of statistically insignificant differences in direction of the answer (completely not applies) having a percentage of $(36.75 \%)$ of total answers. Its relative importance has been (66.25), and its rating, with respect to sentences of scale, has been (23).

Researcher attributes these small differences to that female students are psychologically associated with their lecturer, however, most of them mainly-aim at success and getting degrees.

Discussing results of sentence No. (37): Positive guidance motivates me to perform correctly.

Results show the existence of statistically significant differences in direction of the answer (completely applies) having a percentage of $(70 \%)$ of total answers. Its relative importance has been (76.67), and its rating, with respect to sentences of scale, has been (11).

Researcher attributes this result to that positive guidance is needed by everybody. It is a main requirement of success and motivation. Positive support is the basis of success for any activity.

Discussing results of sentence No. (38): I fear that I do not have abilities that qualify me to perform competition

Results show the existence of statistically significant differences in direction of the answer (occasionally applies) having a percentage of (70\%) of total answers. Its relative importance has been (66.67), and its rating, with respect to sentences of scale, has been (22).

Researcher attributes these results to that many female students have negative feeling towards themselves. This negatively affects their performance.

Discussing results of sentence No. (39): I can perform when I am calm and stable.

Results show the existence of statistically significant differences in direction of the answer (occasionally applies) having a percentage of (48.75\%) of total answers. Its relative importance has been (68.33), and its rating, with respect to sentences of scale, has been (20).

Researcher attributes the result to that many female students need to be calm and stable, to be able to perform correctly. They are affected if there are any external factors affecting their calmness. Many others are not affected by external factors, and so their performance is not affected.

Discussing results of sentence No. (40): I have fitness and an ability to perform competition.

Results show the existence of statistically significant differences in direction of the answer (occasionally applies) having a percentage of (31.25\%) of total answers. Its relative importance has been (49.58), and its rating, with respect to sentences of scale, has been (36).

Researcher attributes the result to that many female students trust their ability and try to use it to reach the right performance; however, many others do not have this ability.

Scale-sentences discussion shows that female students, who learn pole-vault competition, have symptoms of psychological hesitation. This agrees with what have been reached by Feras Hassan 
Abdel-Hussein (1999) (6), Laftah Hameed Soliman (2003) (9), Ahmed Abdel-Zohrah (2005) (1) and Gameel Kazem Gawad (2008) (3). They found in their studies that students learning highly difficult competitions have symptoms of psychological hesitation.

\section{- CONCLUSIONS}

1. Scale of psychological hesitation of pole-vault, which has been designed by researcher, is composed of 40 points distributed on 9 axes, they are (axis of thinking under psychological stresses - axis of changing place and crowd effect - axis of knowing the goal and previous experiences - axis of providing elements of safety - axis of boredom - axis of level and importance of competition - axis of body style and training status - axis of lecturer's role and effect of reward and encouragement - axis knowledge of a person to his abilities).

2. Most of female students in the $4^{\text {th }}$ stage of the faculty of physical education - University of AlSadat city are characterized by a high level of psychological hesitation when performing competition of pole-vault.

3. It has been possible to find a triple calibration for this scale, which is (completely applies occasionally applies - completely not applies).

4. The total degree of scale is (120 degrees), and the minimum limit is (40) degrees.

\section{- RECOMMENDATIONS}

1. Using the scale developed by researcher in appreciating level of psychological hesitation of female students learning competition of pole-vault.

2. Building other psychological scales for other sports characterized by risk and difficulty of performing.

3. Strengthening psychological aspects of learners such as self-confidence and courage, before starting to teach competition of pole-vault.

4. Caring about beginners having high levels of psychological hesitation, as it is difficult for them to learn the competition, in order to avoid possibility of injuries.

\section{- REFERENCES}

1. Ahmed Abdoh Al-Zohrah (2005 AD) - Psychological hesitation of players of gymnastics while performing forward jump on jumping horse - faculty of physical education, University of $\mathrm{Al}$ Qadeseya.

2. Bastawisy Ahmad (1997). Track events and field events (teaching, technique, and training). Dar Al-Fekr Al-Araby.

3. Gameel Kazem Gawad (2008 AD) - Building scale of psychological hesitation for swimming learners while performing vertical jumping into water using legs - Magazine of sciences of physical education $-9^{\text {th }}$ edition $-1^{\text {st }}$ folder - Al Qadeseya University.

4. Sai'ed Abdel-Hameed Al Barghouthy (1986 AD) - The art of relaxation - Al Manahel house for printing and publishing - Nezar Al Taleb \& Kamel Taha Louise (1993 AD) - Sports psychology - Al Hekma house for printing and publishing.

5. Ali Abdullah Khalaf Al Hamdouny (2006 AD) - The effect of a pilot program to reduce psychological hesitation accompanying performance of senior players of many Iraqi clubs of shooting - Master thesis - non published - Faculty of physical education - Al Musel University.

6. Fras Hassan Abdel-Hussein (1999) Designing and building scale of psychological hesitation in sports field - unpublished master thesis - faculty of physical education - Al Basrah University

7. Huda Galal Mohammed Al Bayaty (2005) - Regularizing and building scale of psychological hesitation for senior players of team-sports - Master thesis - unpublished - Babel University.

8. Nezar Al Taleb \& Kamel Taha Louise (1993 AD) - Sports psychology - Al Hekma house for printing and publishing - Bagdad.

9. Laftah Hameed Soliman (2003 AD) (8) - A study entitled "Measuring psychological hesitation for footballers" - faculty of physical education - Al Musel University. 
10. Mohammed Hassan Allawy \& Mohammed Nasr El Din Radwan (1990 AD) - Skill \& Psychological Measures - Dar Al Fikr Al Araby - Cairo.

11. -Edmundson, J.M(1979) Pol vault, basic athletics, Forth edition, London\& Burnup , C.R.E 